Meta

Journal des tradlucteurs

Translators' Journal

\title{
The Translatability of Texts: A Historical Overview
}

\section{Raquel de Pedro}

Volume 44, numéro 4, décembre 1999

URI : https://id.erudit.org/iderudit/003808ar

DOI : https://doi.org/10.7202/003808ar

Aller au sommaire du numéro

Éditeur(s)

Les Presses de l'Université de Montréal

ISSN

0026-0452 (imprimé)

1492-1421 (numérique)

Découvrir la revue

Citer cet article

de Pedro, R. (1999). The Translatability of Texts: A Historical Overview. Meta, 44(4), 546-559. https://doi.org/10.7202/003808ar d'utilisation que vous pouvez consulter en ligne.

https://apropos.erudit.org/fr/usagers/politique-dutilisation/ 


\title{
The Translatability of Texts: A Historical Overview
}

\author{
RAQUEL DE PEDRO \\ University of Abertay, Dundee (Scotland), U.K.
}

\begin{abstract}
RÉSUMÉ
Cet article étudie les diverses approches de l'intraduisibilité des textes en portant une attention spéciale aux théories des $19^{\mathrm{e}}$ et $20^{\mathrm{e}}$ siècles. On analyse les points de vue des chercheurs qui ont adopté une position monadiste (par ex. Edward Sapir) et ceux qui ont choisi une interprétation universaliste (Eugene A. Nida, par ex.). On affirme que le déport de l'attention du concept de l'intraduisibilité, qui a caractérisé les théories récentes, n'est que superficiel et que cela tire son origine, d'une part, de l'élargissement du concept de traduction lui-même, et d'autre part, dépend du désir d'oublier des arguments traditionnels et idéologiquement modifiés qui pourrraient être perçus comme problématiques.
\end{abstract}

\begin{abstract}
This paper critically surveys the different approaches to the (un)translatability of texts, giving special attention to the theories generated in the nineteenth and twentieth centuries. It analyses the views of scholars who adopted a monadist stance (such as Edward Sapir) and those who chose a universalist interpretation (Eugene A. Nida, for instance). It is argued that the shift of attention away from the concept of untranslatability, which has characterised recent theories is only superficial and that it has resulted, on the one hand, from the expansion of the concept of translation itself and, on the other, from a wish to leave behind traditional, ideologically motivated arguments which could be perceived as problematic.
\end{abstract}

There are essentially two points of view from which translatability has been traditionally approached: the universalist one and the monadist one. ${ }^{1}$ Supporters of the former approach claim that the existence of linguistic universals ensure translatability. Those who endorse the latter approach maintain that each linguistic community interprets reality in its own particular way and this jeopardises translatability. The polarisation of thought which these two opposed approaches imply has not always been manifest in translation scholarship. Some theorists have oscillated between the extremes represented by universalism and monadism and some have attempted to combine aspects of both perspectives. There is a third, more recent approach to translatability: that of the Deconstructionists, who question the notion of translation as transfer of meaning.

The issue of the translatability of texts started to be considered as such in the nineteenth century, when the birth of a linguistic science encouraged the positing of theoretical questions of this nature. Until then, scholars had focused their attention mainly on translation methodology and the principles of translation. The development of theories on the nature of language and communication provided a growing medium for an analysis of the possibility or impossibility of elaborating concepts in a language different from that in which they were conceived. 
Up to the eighteenth century there seemed to exist a certain tacit consensus as to the interchangeability of linguistic codes. However, Leibniz's philosophical approach to language began to point in a different direction. As early as 1697, in Steiner's words (1992: 78), "Leibniz put forward the all-important suggestion that language is not the vehicle of thought but its determining medium". Many translators and theorists would adhere to monadist postulates fostered by this approach in centuries to come. According to Steiner, "[f]rom the 1750's onward, the problem of 'l'influence réciproque du langage sur les opinions et des opinions sur le langage' was very much in vogue" (ibid.: 79). Universalist approaches, on the other hand, were also common currency. ${ }^{2}$

In the nineteenth century, linguists such as von Humboldt, Schlegel, Schleiermacher and Schadewaldt considered each language immeasurable in its own individuality. Hence the translation theories of that age, which signalled two possible, incompatible paths for the translator: one of them leading towards the source language/source culture and the other one, towards the target language/target culture. The links between both were, in a way, ignored, and no compromise solution, no "middle way" contemplated. Von Humboldt's words, from a letter to A.W. Schlegel, dated July 23, 1796, exemplify this approach to translation:

All translation seems to me simply an attempt to solve an impossible task. Every translator is doomed to be done in by one of two stumbling blocks: he will either stay too close to the original, at the cost of taste and the language of his nation, or he will adhere too closely to the characteristics peculiar to his nation, at the cost of the original. The medium between the two is not only difficult, but downright impossible (Wilss, 1982: 35).

Nevertheless, his own experience as a translator made von Humboldt perceive the need for translation: "translation is one of the most necessary tasks of any literature" (in Schulte \& Biguenet, 1992: 56). According to his hypothesis, the structural differences which exist between languages are no obstacle for translation. The reason that von Humboldt proposes to explain this is that each linguistic community has a potential of expression which can generate resources for verbalising every extralinguistic area, even those which go beyond its own social and cultural experience. To apparent untranslatability, which results from structural incompatibilities between languages, one can respond with potential translatability, with the possibility of expressing the concepts of human experience in any human language (see Wilss, 1982: 35 ff.).

Leo Weisgerber anticipated the hypothesis of the existence of a sprachliche Zwischenwelt, a linguistic mediary world, which controls thought. He proposed the theory ${ }^{3}$ that "our understanding is under the spell of the language which it utilizes" (Steiner, 1992: 90). This view was also sustained in the early 1930's by Jost Trier. Edward Sapir and Benjamin Lee Whorf, his disciple at Yale, also exploited this hypothesis in America, where anthropological study of native American cultures had opened new paths to linguistics. Sapir asserted in 1929 that "the 'real world' is to a large extent unconsciously built up on the language habits of the group. [...] The worlds in which different societies live are distinct worlds, not merely the same world with different labels attached." (Steiner, 1992: 91). This hypothesis would be elaborated, through the 1930's and 1940's, into a theory according to which the fact that 
each linguistic community has its own perception of the world, which differs from that of other linguistic communities, implies the existence of different worlds determined by language. ${ }^{4}$

What has become known as the Sapir-Whorf hypothesis is generally not applied in its strongest form, since this would imply the impossibility of effective communication between the members of different linguistic communities. However, a "moderate" version of this hypothesis has been justified through numerous examples extracted from different (often remote) languages, in relation to, for instance, the semantic fields of colour, family and weather, or the tense configuration of verbal systems.

This different perception and mental organisation of reality can be used to explain the existence of certain "gaps" between languages, which can turn translation into a very difficult process. Translators have to be aware of these gaps, in order to produce a satisfactory target text. Acceptance of the hypothesis that each language conditions the way in which its speakers perceive and interpret the world presupposes:

a. That there will be terms which are specific to each linguistic community.

b. That there will be concepts which are common to two or more linguistic communities and nevertheless have different connotations in each of them.

c. That each linguistic community structures reality in a different way, according to its own linguistic codes.

All these factors have to be borne in mind when approaching the translation of any text. They can give rise to translatability problems, but the fact that they apply to very specific items which can be distinctly outlined implies that they cannot support a hypothesis of total untranslatability. That is, the impossibility of translating a text does not follow from the recognition of these circumstances.

In 1923, Walter Benjamin published his German translation of Baudelaire's Tableaux Parisiens. In the introduction to this book, an essay entitled "The Task of the Translator", Benjamin outlines his theory on the translatability of texts. For Benjamin, "the law governing the translation: its translatability" (1992: 71) has to be found in the original. He considers the translatability of a given work as having "a dual meaning. Either: Will an adequate translator ever be found among the totality of its readers? Or, more pertinently: Does its nature lend itself to translation and [...] call for it? [...] Only superficial thinking will deny the independent meaning of the latter and declare both questions to be of equal significance" (ibid.). In Benjamin's view, the translatability of a text is independent of whether or not such text can be translated. This is the reason why he asserts: "Translatability is an essential quality of certain works, which is not to say that it is essential that they be translated; it means rather that a specific significance inherent in the original manifests itself in its translatability." (ibid.)

The question of the significance of a text is central to Benjamin's theory. This significance transcends both the content and the form of the text:

The transfer can never be total, but what reaches this region is that element in a translation which goes beyond transmittal of subject matter. This nucleus is best defined as the element that does not lend itself to translation. Even when all the surface content has been extracted and transmitted, the primary concern of the genuine trans- 
lator remains elusive. Unlike the words of the original, it is not translatable, because the relationship between content and language is quite different in the original and the translation. (ibid.: 76)

The elusiveness of the true significance of a text in Benjamin's theory does not derive from incompatibility between languages. On the contrary, he elaborates on the "kinship of languages", which he sees founded on that very same significance: "Languages are not strangers to one another, but are, a priori and apart from all historical relationships, interrelated in what they want to express." (ibid.: 73). It is in translation that we can catch a glimpse of "pure language": "to turn the symbolizing into the symbolized, to regain pure language fully formed in the linguistic flux, is the tremendous and only capacity of translation. [...] It is the task of the translator to release in his own language that pure language which is under the spell of another, to liberate the language imprisoned in a work in his re-creation of that work." (ibid.: 80).

Benjamin's theory remains very much a philosophical exercise. On occasion, he uses theology to justify a paradoxical remark: "One might, for example, speak of an unforgettable life or moment even if all men had forgotten it. If the nature of such a life or moment required that it be unforgotten, that predicate would not imply a falsehood but merely a claim not fulfilled by men, and probably also a reference to a realm in which it is fulfilled: God's remembrance." (ibid.: 71). Other paradoxes are not elaborated upon: "The lower the quality and distinction of its [the original's] language, the larger the extent to which it is information, the less fertile a field it is for its translation, until the utter preponderance of content, far from being the lever for a translation of distinctive mode, renders it impossible. The higher the level of a work, the more it does remain translatable even if its meaning is touched upon only fleetingly." (ibid.: 81).

Some of the concepts he presents are vague. Although he defines: "Translation is a mode" (ibid.: 71), it remains unclear what he means by this assertion. The mission of the translator is, according to Benjamin, to echo the original (ibid.: 77) in a new language. The idea of an "echo" is as nebulous as that of the purity of language: "In translation the original rises into a higher and purer linguistic air, as it were" (ibid.: 75).

Benjamin deliberately sought to dissociate translations (and literature generally) from their readerships: "In the appreciation of a work of art or an art form, consideration of the receiver never proves fruitful." (ibid.: 70). In doing so, he chose to ignore the consideration that the translator, as a receiver of the original and the link between this and the translated text, deserves. Also, that translations which are produced for commercial purposes (as most translations of literary works are) are biased by the expectations of their audiences, who often look more for the likeness to the original which Benjamin claims would make translation impossible (ibid.: 73), than for a reflection of pure language and a significance which may link all languages.

In a series of reading workshops which started at Harvard in the late 1920's, I. A. Richards laid the foundations for his theory of translating, based on his belief that there is a "proper" way of decoding a text and recoding it in a different language. ${ }^{5}$ Thus, as Gentzler remarks, Richards "maintained that the literary scholar could develop rules of solving a communication problem, arrive at a perfect understanding, and correctly reformulate that particular message." (1993: 17). The most basic flaw in Richard's theory, leaving aside the questionability of concepts such as "perfect" and "correctly", is that it can be easily contradicted from real-life experience: presented 
with the same text, different translators would, more likely than not, produce dissimilar "recodings".

Frederic Will shared much of the conceptual basis of the New Criticism pioneered by I. A. Richards. Nevertheless, his experience as a translator made him depart from the deceptive straightforwardness which derived from Richard's thought. In Literature Inside Out (1966), he appeared to support a moderate version of the SapirWhorf theory: "Reality can only be learned [...] through the names we give it, and so, to a certain degree, language is the creator of reality" (in Gentzler, 1993: 29). However, in The Knife and the Stone (1973), he turns to the elitist notions which had been championed by Richards in order to elaborate his literary theory: "The inter-translatability of languages is the firmest testing ground, and demonstration ground, for the existence of a single ideal body of literature." (in ibid.: 31). Thus, as Gentzler observes, Will was caught in a paradox: "That which makes it possible for Will (universals/deep structures) also makes it impossible (the specific moment/surface structures).” (ibid.: 36). In other words, although Will believed in the existence of linguistic universals, he saw their actual manifestations as being distinctive of each linguistic community. Therefore, even if common structures underlie all human languages, their surface counterparts are so different in each of those languages that translation may become an impossible task.

Some theorists accepted the existence of incompatibilities between languages, but did not deny the concept of translatability itself. On the contrary, alternative forms of translation to a literal decoding-recoding process were called for ${ }^{6}$. When in 1967 C. L. Wren gave the Presidential Address of the Modern Humanities Research Association entitled "The Idea of Comparative Literature", he suggested that:

Clearly fundamental differences in patterns of thinking among peoples must impose relatively narrow limits. An African language, for example, is incompatible with a European one for joint approaches in Comparative Literature study. Even Sanskrit, though itself an Indo-European language along with its Indian ramifications, presents a pattern of thought which renders any sort of literal translation of very limited value. (Bassnett, 1993: 19-20)

The belief in linguistic universals, a notion which underlies the views of all those who, from the eighteenth century onwards, adhered to a general translatability approach to literature, would become the basis for Noam Chomsky's generative transformational grammar. However, Chomsky himself warned scholars against the applicability of his theory in the field of translation:

The existence of deep-seated formal universals [...] implies that all languages are cut to the same pattern, but does not imply that there is any point by point correspondence between particular languages. It does not, for example, imply that there must be some reasonable procedure for translating between languages. (Gentzler, 1993: 50).

Many, however, ignored Chomsky's cautionary words. From the 1960's onwards, supporters of the universal translatability notion used the theory formulated in $A s$ pects to give their views scientific foundation. Some of the most prominent twentieth-century linguists (Jakobson, Bausch, Hauge, Nida ${ }^{7}$ and Ivir, amongst others) accept the view that, in principle, everything can be expressed in any language. Those who support this view argue that the translatability of a text is guaranteed by the existence of universal syntactic and semantic categories and endorsed by the logic of 
experience. In Nida's words: "that which unites mankind is greater than that which divides"8 (1964: 2).

Other scholars, however, do not adhere to this theory of universal translatability. André Martinet, for example, propounds in Eléments de Linguistique Générale (1960) that human experience is incommunicable, because it is unique. The reason he adduces is that each language structures the data acquired through experience in its own individual way and, in doing so, he takes on board the implications of the SapirWhorf hypothesis.

Along the same lines, Hugo Friedrich argues in "Zur Frage der Übersetzungskunst" (1965) that "literary translations continue to be threatened by the boundaries that exist between languages. Thus, the art of translation will always have to cope with the reality of untranslatability from one language to another." (Schulte \& Biguenet, 1992: 11).

J. C. Catford proposed a method in order to assess the translatability of texts, based on the degree to which a given text can be contextualised in the target language, taking into consideration all linguistic and extralinguistic factors. He places the absolute limits to translatability on two axes (1965: chap. 7):

1. Translation between media is impossible (the oral form of a text cannot be translated into the written form of a given text, and vice versa).

2. Translation between what he calls the "medium-levels" (phonology and graphology) and the grammatical and lexical levels is impossible (source language phonology cannot be translated into target language grammar, and so on).

Thus, according to Catford, in order for textual equivalence to exist, source language and target language elements must have some essential features in common. His premises can, however, be contradicted by practical evidence. It is conceivable for a translator to put in written form his/her translation of an oral text. Also, phonological devices of the source text (such as rhyme, for example), can be compensated in the target text by means of syntactical elements (some form of iteration), thus "translating" the rhythm of the text.

Some scholars working in the field of translation assume, implicitly or explicitly, the existence of a basic division within untranslatability: that between linguistic untranslatability and cultural untranslatability. This means that a dichotomy can be established between the translation difficulties that have their origin in the gap between source language and target language, and those which arise from the gap between source culture and target culture. The theories of these scholars will be explained in the paragraphs below.

Catford pioneered in British Translation Studies a rationalisation of this issue. He considered that the validity of the above differentiation between linguistic and cultural untranslatability is questionable. He proposes the following definitions in $A$ Linguistic Theory of Translation:

Linguistic untranslatability: "failure to find a TL [target language] equivalent is due entirely to differences between the source language and the target language" (Catford, 1965: 98). Some examples of this type of untranslatability would be ambiguity, plays on words, oligosemy, etc.

Cultural untranslatability arises "when a situational feature, functionally relevant for the SL [source language] text, is completely absent from the culture of which the TL 
[target language] is a part" (ibid.: 99). For instance, the names of some institutions, clothes, foods and abstract concepts, amongst others.

According to Catford's view of the question, the dichotomy mentioned above would not exist if it could be demonstrated that all instances of cultural untranslatability respond to "the impossibility of finding an equivalent collocation in the TL [target language]" (ibid.: 101). This impossibility is, in his opinion, a case of linguistic untranslatability. More specifically, it is a case of "collocational untranslatability", which Catford defines as: "untranslatability arising from the fact that any possible TL [target language] near-equivalent of a given SL [source language] lexical item has a low probability of collocation with TL equivalents of items in the SL text which collocate normally with the given SL item" (ibid.).

The practical implications of reducing cultural untranslatability to a form of linguistic untranslatability would greatly affect the field of machine translation, since a computer could hypothetically be programmed to recognise such anomalous collocations. However, it seems that there is more to cultural untranslatability than just a matter of collocation. The question of how the target audience may interpret cultural issues in the source text also forms part of the considerations which have to be borne in mind when approaching the question of translatability.

Anton Popovic also outlines a differentiation between linguistic and cultural untranslatability in A Dictionary for the Analysis of Literary Translation (1976). He defines the former as: "A situation in which the linguistic elements of the original cannot be replaced adequately in structural, linear, functional or semantic terms in consequence of a lack of denotation or connotation" (Bassnett-McGuire, 1980: 34).

This categorisation is very similar to the one proposed by Catford a decade earlier. However, the definition of cultural untranslatability which Popovic proposes is substantially different from that of Catford: "A situation where the relation of expressing the meaning, i.e. the relation between the creative subject and its linguistic expression in the original, does not find an adequate linguistic expression in the translation" (ibid.). Catford's initial approach when studying the issue of cultural untranslatability shows a fundamentally linguistic nature, whereas Popovic's, as Basnett-McGuire indicates, implies a theory of literary communication.

Nida and Charles R. Taber pronounce: "Anything that can be said in one language can be said in another, unless the form is an essential element of the message" (1969: 4), thus disregarding the possibility of the existence of cultural untranslatability. This assertion is particularly relevant to the translation of literary texts, since the aesthetic function of language is of prime importance in this kind of text and, as a result, formal considerations are essential. Other scholars, on the other hand, claim that the external boundaries of translatability can be determined by the genre of the text. George Steiner states: "Not everything can be translated. Theology and gnosis posit an upper limit" (1992: 249); ${ }^{9}$ and "Nonsense rhymes, poésie concrète, glossolalia are untranslatable because they are lexically non-communicative or deliberately insignificant"10 (ibid.: 296).

What seems undeniable is that some texts are more easily translatable than others. In general, it can be asserted that a text with an aesthetic function will contain elements which will make its reproduction in a different language difficult, whereas a text with a merely informative function will be easier to translate. The use of language with an aesthetic function is more self-conscious and will presuppose a greater 
degree of elaboration than language with a merely communicative function. As a result, intentionality in the source text plays a very important role, which conditions the translator to attempt the reproduction in the target text of the elements which the original author presented intentionally.

Since the question of translatability versus untranslatability began to be considered, the need has been felt by some scholars to produce a taxonomy of text types according to their degree of translatability. In the article "Invariantz und Pragmatik", published in 1973, Neubert established a classification in four different categories (Wilss, 1982: 114):

1. Texts which are exclusively source-language oriented: Relatively untranslatable.

2. Texts which are mainly source-language oriented (literary texts, for example): Partially translatable.

3. Texts which are both source-language and target-language oriented (as the texts written in language for specific purposes): Optimum translatability. ${ }^{11}$

4. Texts which are mainly or solely target-language oriented (propaganda, for instance): Optimum translatability.

The validity of this classification is arguable, since the limits established between the different degrees of translatability are vague (for example, no distinction is made between literary sub-genres) and arbitrary (the translator can use paraphrasis in order to make the degree of translatability of a source-language oriented text identical to the one of a source and/or target-language oriented text).

Besides, the correlation which Neubert established between a text and its degree of translatability, on the one hand, and its level of translation equivalence (a problematic concept in itself), on the other, is not always straightforward, since within a text characterised by theoretical optimum translatability there can be found relatively untranslatable passages.

Georges Mounin, for his part, states: “...la théorie de l'intraduisibilité est construite toute entière sur des exceptions" (Wilss, 1982: 41). However, at the same time that he maintains, along the same lines as Neubert did, that the notion of untranslatability is relative, he expresses his conviction that translation is only possible to an extent, within certain parameters. In order to define the limits of translatability, translation failure has to be measured in a given text and a given pair of languages (see Mounin, 1977: 312). On the other hand, Mounin considers that there are more pressing, tangible problems which the translator has to face. According to his view, more attention should be devoted to solving these problems than to speculating on the translatability or untranslatability of the texts.

Other authors accept a universal translatability hypothesis, with certain reservations. Wilss states: "To agree with the principles that texts are translatable is not to postulate the unlimited translatability of all texts in general" (Wilss, 1982: 47). He also quotes Weisgerber's elaboration on this issue: “...the serious translator believes, in effect, that a perfect translation from one language to another is not possible" (Wilss, 1982: 41), but then presents a more radical principle: "everything can be expressed in every language", a principle which, he claims, is "widespread in modern linguistics" (Wilss, 1982: 48). For him:

The translatability of a text is [...] guaranteed by the existence of universal categories in syntax, semantic, and the (natural) logic of experience. Should a translation neverthe- 
less fail to measure up to the original in terms of quality, the reason will (normally) be not an insufficiency of syntactic and lexical inventories in that particular TL [target language], but rather the limited ability of the translator in regard to text analysis. (Wilss, 1982: 49)

On the other hand, the inter-relatedness of language and culture and its implications for translation still form part of the theories of some scholars, like Winter, who accepts the impossibility of a perfect translation, on a principle reminiscent of the Sapir-Whorf hypothesis: "If an interpretation of reality as formulated in language A does not exist in any isolation, but only as part of the total system of this language, then its correlative in language $\mathrm{B}$ cannot be isolated from the overall system of $\mathrm{B}$, which must be different from that of A" (Larose, 1989: 107).

In the late 1960's, a new current of thought, Deconstructionism, emerged in France. It would revolutionise translation theory in years to come. From the late 1970's onwards, Andrew Benjamin, Michel Foucault, Paul de Man and Jacques Derrida, most significantly, called for a new approach to translation. It is claimed that the translation of a text affects the way in which that text is perceived and, therefore, there is a "re-writing" of the original through translation. Target texts cease to be considered as subsidiaries of the original, which, in turn, becomes dependent on translation. After all, following Venuti's interpretation of poststructuralist philosophy, "What makes the foreign text original is that it is deemed worthy of translation" (1992: 7). This is to say, the act of translating constitutes a validation of the text that is being translated. Originality ceases to be a chronological concept (i.e. it is not about which text was produced first) and becomes a qualitative matter (i.e. it refers to the nature of the text which was conceived first). ${ }^{12}$ The question of authorship itself is challenged and translation is seen as a process in which language is constantly modifying the source text. ${ }^{13}$ In Language, Counter-memory, Practice (1977), Foucault outlines the importance of this diachronic approach, recommending an analysis of texts within their historical situation (see Gentzler, 1993: 150).

Jacques Derrida rejects the notion of the existence of kernels or deep structures, to follow Chomsky's terminology, which underlie language. Thus, language itself acquires a new identity of its own, and not merely as a form of representing meaning. Gentzler observes that, for deconstructionists, "In translation, what is visible is language referring not to things, but to language itself" (1993: 147). This concept is fundamental for postmodern theory and also for postmodern literature, of which the autonomy and self-reflectiveness of language is very much a defining feature. But this approach is not entirely new. In "The Task of the Translator", Walter Benjamin had anticipated the idea that language does not refer to any objective reality: "In this pure language -which no longer means or expresses anything but is as expressionless and creative Word, that which is meant in all languages- all information, all sense, and all intention finally encounter a stratum in which they are destined to be extinguished" (1992: 80). As Bassnett remarks: "Benjamin's essay was rediscovered by translation theorists in the 1980s, ${ }^{14}$ and has become one of the most significant texts of postmodern translation theory." (1993: 151).

For Derrida, "translatability as transfer of meaning is the very thesis of philosophy." (Niranjana: 1992: 55). He criticises the approaches to translation which are based on the existence of a meaning which transcends language, because "the theme of a trascendental signified took place within the horizon of an absolute pure, trans- 
parent, and unequivocal translatability" (1981: 20). Derrida proposes a new approach to this issue:
"In the limits to which it is possible, or at least appears possible, translation practises the difference between signified and signifier. But if this difference is never pure, no more so is translation, and for the notion of translation we would have to substitute a notion of transformation: a regulated transformation of one language by another, of one text by another." (ibid.)

Derrida is aware of the losses which are bound to occur when presenting the source text in the target language. For this reason, "With each naming gesture, Derrida suggests a footnote, a note in the margin, or a preface also is in order to retrieve those subtle differing supplementary meanings and tangential notes lost in the process of transcription.” (Gentzler, 1993: 146).$^{15}$ His philosophy presents a stimulating approach to translation, but Derrida's line of thought leads to the questioning of the very concept from which his theory starts: what is translation? It can be argued that translatability does not equal the possibility of explaining a text. ${ }^{16}$ Besides, translations are not usually academic exercises. They are produced for a readership that has certain expectations about what the target text should look like. In the case of commercial translation especially, notes and prefaces tend not to be welcomed by the readers, if nothing else, because they are distracting.

Any text can be explained, and yet translation is concerned with issues that go beyond an elucidation of the source text in a foreign language. If translation aims at providing a reading experience comparable to that of the source text, it can be argued that an explanation or a gloss would fail to meet the expectations of the target text readers.

None of the theories proposed until now appears to be fully satisfactory. Nida has expressed repeatedly the need for a better differentiation in the debate on translatability versus untranslatability, since he claims that no valid conclusion can be reached starting from a simplistic, ideologically motivated system. There still remain, nevertheless, some political considerations which are borne in mind by some theoreticians. Otto Kade's words, quoted below, illustrate the main focus of this trend of thought: ${ }^{17}$

The conception of untranslatability has its roots in idealistic philosophy. The denial of translatability presupposes a subjective ranking of the various languages [...]. Since a language cannot be thought of as existing independently of those who speak it, [...] we find ourselves on the surest road to a reactionary racist ideology. (Wilss, 1982: 46)

According to this, postulating the untranslatability of a text implies sustaining the view that some languages are not apt for expressing certain aspects of human experience. A hierarchical classification of languages according to the complexity of their resources or their sophistication would entail an implicit hierarchical organisation of the speakers of the different languages. As a result, such classification would foster the notion that the superiority or inferiority of people lies with their ethnic or national characteristics, to which languages are associated.

This proposition seems too extreme, since the acceptance of differences between linguistic communities does not necessarily presuppose the establishment of a hierarchical classification. Each community perceives the world and expresses its experience of it in a different way, according to its needs. Considering what is different as 
inferior is, certainly, a reactionary stand. Yet there is no direct or necessary relation between the concepts of difference, on the one hand, and inferiority or superiority, on the other.

Since the early attempts at establishing a scientific theory of the problem, translation theory has covered much ground and progressed considerably. At the same time, it has become notably diversified, benefitting from notions which derive from various knowledge areas, which are, in principle, external and yet related to translation as a discipline (for example, sociology, psychology, applied linguistics and narratology). As a result of all this, the debate on (un)translatability has been relegated to a marginal position within what is probably the most influential current of thought in translation in recent times, ${ }^{18}$ Translation Studies. In the words of BassnettMcGuire (1980: 66), "with the shift of emphasis away from the formal processes of translation, the notion of untranslatability would lead on to the exaggerated emphasis on technical accuracy and resultant pedantry of later nineteenth-century translating".

At present, there is a tendency to presuppose that most texts are translatable, however different the understanding of the nature of translation may be amongst scholars. ${ }^{19}$

This can lead to the conclusion that the issue of untranslatability is nowadays being considered and assessed under different names, different "tags". Studies on cultural issues in translation and on the difficulties of cross-cultural communication $^{20}$ have flourished in recent times. The titles of some of them speak for themselves: Translation, History and Culture (1990), edited by Susan Bassnett and André Lefevere; Translation/History/Culture. A Source Book (1992), edited by André Lefevere; or Communication Across Cultures (1997), by Basil Hatim. As Gentzler remarks, "Bassnett and Lefevere argue that Translation Studies is taking an historic 'Cultural Turn' as it propels itself into the nineties." (1993: 185). A clear sign of this is that, in the essay entitled "Linguistic Transcoding or Cultural Transfer? A Critique of Translation Theory in Germany", Snell-Hornby proposes that translation scholars move from "text" to "culture" as a translation unit (Bassnett and Lefevere, 1990: 5).

The notion of taking culture as a translation unit is very attractive. However, whereas it is easy to comprehend the translation of a text as a self-contained process, it is possible to argue that culture cannot be translated. Culture can be explained or interpreted in its specific manifestations, but it would appear that "translation" is too restrictive a concept to be applied in this case. That which is understood by the readers of the source text merely because they belong to the source culture is what makes the text relatively untranslatable: it will not be grasped by the readers of the target text merely because of their belonging to a different cultural and/or linguistic community.

To sum up, the consensus now seems to be that absolute untranslatability, whether linguistic or cultural, does not exist. The notion of untranslatability has been unpopular in the twentieth century mainly due to ideological reasons. With the expansion in the concept of translation in the twentieth century, the debate on translatability versus untranslatability loses part of its validity, since the various strategies that translators can resort to when confronted with a gap between two languages or two cultures are acknowledged as sound translation mechanisms. At the same time, it is assumed that the perfect translation, i.e. one which does not entail any losses from the original is unattainable, especially when dealing with literary 
translation. A practical approach to translation must accept that, since not everything that appears in the source text can be reproduced in the target text, an evaluation of potential losses has to be carried out. To quote Senn's words, "That nothing is negligible [...] is not a principle that could possibly survive in translation. Priorities must be set." (Snell-Hornby \& Pöhl, 1989: 79).

\section{NOTES}

1. In "La miseria y el esplendor de la traducción" (1939), the Spanish philosopher José Ortega y Gasset placed the issue of untranslatability in a wider philosophical frame, which expands beyond linguistic considerations. For Ortega, all human actions and endeavours are essentially utopian. Therefore, the act of translating is also a utopian task (see Schulte \& Biguenet, 1992: 93-112).

2. See Steiner, 1992: 76-82, for an overview of this matter.

3. Weisgerber developed this theory in a series of books published between 1929 and 1950 (see Steiner, 1992: 90).

4. Steiner (1992: 81) sees an antecedent of Sapir/Worf's linguistic relativism in J.G. Hamann's Philologische Einfälle und Zweifel, published in 1772.

5. Cf. Benjamin, 1992: 70: "the concept of an 'ideal' receiver is detrimental in the theoretical consideration of art". Benjamin had thus anticipated and rejected one of the principles on which Richards based his theory.

6. This approach is controversial, in that it implied a hierarchy of languages and, by extension, of cultures. See below (Otto Kade's views) for an elaboration of this issue.

7. Eugene A. Nida claims that his own postulate of language universals, on which he bases his translation theory, preceded Chomsky's. In an article entitled “A Framework for the Analysis and Evaluation of Theories of Translation" (1976), he states: "Before the formulation of generative-transformation grammar by Chomsky Nida had already adopted an essentially deep-structure approach to certain problems of exegesis." (in Gentzler, 1993: 44).

8. It is worth noting here that Nida's assertion, stemming from his humanitarian (in the sense that it seeks to promote the welfare of mankind), evangelical philosophy, encompasses both the linguistic and the cultural aspects of translation. Thus, he adds a cultural perspective to Chomsky's theory of linguistic universals.

9. Cf. Benjamin (1992: 82): "Where a text is identical with truth or dogma, where it is supposed to be 'the true language' in all its literalness and without the mediation of meaning, this text is unconditionally translatable."

10. Steiner emphasises the role of the meaning of such texts. However, if their formal characteristics cannot be reproduced in the target language, what arises would be a case of linguistic untranslatability.

11. Neubert defines "optimum translatability" as the degree which is obtained when denotative translation equivalence is the essential qualitative reference frame.

12. A similar standpoint was adopted by the Mexican poet Octavio Paz in Traducción: Literatura y Literalidad (1971). In Irene del Corral's translation: "No text can be completely original because language itself, in its very essence, is already a translation-first from the nonverbal world, and then, because each sign and each phrase is a translation of another sign, another phrase. However, the inverse of this reasoning is also entirely valid. All texts are originals because each translation has its own distinctive character. Up to a point, each translation is a creation and thus constitutes a unique text." (in Schulte \& Biguenet, 1992: 154).

13. For a fictionalisation of a similar postulate, which precedes formal Deconstructionist theory, see Pierre Menard, autor de El Quijote, by Jorge Luis Borges, originally published in Sur, n. 56, Buenos Aires, 05/1939 (pp. 7-16). Menard undertook the task of re-writing El Quijote word by word, without, nevertheless copying the novel. In "Los traductores de las 1001 Noches" (in Historia de la eternidad, first published in 1936) Borges had anticipated the notion of translators altering future perceptions of the source text: "Galland establece un canon, incorporando historias que har( indispensables el tiempo y que los traductores venideros -sus enemigos- no se atreverán a omitir” (1953: 100). He also emphasised the influence of literary tradition in the reception and interpretation of a translated text. 
14. In fact, the "rediscovery" of this essay had happened before the 1980's. Gentzler (1993: 174) states: “The first deconstructionist reading of Benjamin's essay can probably be located in Carol Jacobs 1975 essay 'The Monstrosity of Translation' “.

15. Nabokov before Derrida supported this view, too: "I want translations with copious footnotes, footnotes reaching up like skyscrapers to the top of this or that page so as to leave only the gleam of one textual line between commentary and eternity. I want such footnotes and the absolute literal sense, with no emasculation and no padding" (in Schulte \& Biguenet, 1992: 143).

16. Vladimir Nabokov took a radical stand on this issue in the foreword to his translation of Eugene Onegin: "The term 'literal translation' is tautological since anything but that is not truly a translation but an imitation, an adaptation or a parody." (in Schulte \& Biguenet, 1992: 134).

17. A different political stand is the one held by those who suscribe to the views of Lawrence Venuti, who states that "any attempt to make translation visible today is a political gesture" (1992: 10). This point of view, although different in its conception to Kade's, is, however, implicitly related to the issue of ranking of languages. According to Venuti, the language spoken by a culturally dominant community can be used in translation as part of an act of imperialism against the language spoken by a less prominent community.

18. The wide diffusion of the works of Itamar Even-Zohar, Gideon Toury, Susan Bassnett, Theo Hermans and André Lefevere, amongst others, and their academic prestige seems to justify this assertion.

19. One of the most provocative approaches is that advocated by two followers of the Brazilian Antropofagista Movement, Haroldo and Augusto de Campos, who also cultivate poésie concrète. The Antropofagista movement, pioneered by Oswald de Andrade, when concerned with translation, interprets the process as a form of cultural cannibalism. As Else Veira puts it, "the 'receiving' culture will interpenetrate and transform the original one [...] translation is no longer a one-way flow from the source to the target culture, but a two-way transcultural exercise" (in Bassnett, 1993: 155).

20. The difficulties of cross-cultural communication are magnified in translation, given that the author of the original text, in producing that text, was communicating with his/her readership within the parameters of one shared language. Cross-cultural communication by means of translation is normally carried out through an intermediary (the translator) and is, therefore, subject to alterations which, in general, are alien to the author, the primary communicator.

\section{REFERENCES}

Bassnett-McGuire, Susan (1980): Translation Studies, London, Methuen.

- (1993): Comparative Literature. A Critical Introduction, Oxford UK \& Cambridge USA, Blackwell.

Bassnett, Susan \& André Lefevere (eds.) (1992): Translation, History and Culture, London \& New York, Routledge.

Benjamin, Walter (1992): Illuminations (tr. Harry Zohn), London, Fontana Press.

Borges, Jorge Luis (1953): Historia de la eternidad, Buenos Aires, Emece.

— (M. Enguídanos, ed.) (1970): Borges, Sus Mejores Páginas, New Jersey, Prentice-Hall Inc. CATford, J. C. (1965): A Linguistic Theory of Translation, London, Oxford University Press.

DerridA, Jacques (1981): Positions (tr. Alan Boss), London, The Athlone Press.

Gentzler, Edwin (1993): Contemporary Translation Theories, London \& New York, Routledge.

LARose, Robert (1989): Théories contemporaines de la traduction, Québec, Presses de l'Université du Québec.

Mounin, Georges (1977): Los problemas teóricos de la traducción (tr. Julio Lago Alonso, Madrid, Gredos.

NidA, Eugene A (1964): Toward a Science of Translating, Leiden, E.J. Brill.

NidA, Eugene A. \& Charles R. TABER (1969): The Theory and Practice of Translation,Leiden, E.J. Brill.

Niranjana, Tejasinini (1992): Siting Translation. History, Post-structuralism and the Colonial Context, Berkeley, University of California Press.

Schulte, Rainer \& John Biguenet (eds.) (1992): Theories of Translation: An Antology of Essays from Dryden to Derrida, Chicago \& London, University of Chicago Press. 
Snell-Hornby, Mary \& Esther Pöhl (eds.) (1989): Translation and Lexicography,Missouri, John Benjamins B.V./Paintbrush/Euralex.

Steiner, George (1975): After Babel. Aspects of Language and Translation, Oxford, Oxford University Press.

Venuti, Lawrence (1992): Rethinking Translation,London \& New York, Routledge.

Wilss, Wolfram (1982): The Science of Translation. Problems and Methods, Tübingen, Gunter Narr Verlag. 